\title{
Os jogos do Instituto Federal do Paraná: um estudo sobre as percepções e práticas dos coordenadores de ações esportivas
}

\section{RESUMO}

Este estudo objetivou analisar as percepções e práticas dos coordenadores de ações esportivas do IFPR sobre os Jogos do Instituto Federal do Paraná. Trata-se de uma pesquisa qualitativa descritiva, na qual foi aplicada uma entrevista semiestruturada com os quatro coordenadores envolvidos com a gestão dos JIFPR no período de 2010 a 2021. Os dados foram categorizados e analisados mediante a análise de conteúdo. Por meio dos discursos foi possível apreender-se as construções, as relações e a importância deste evento no contexto em análise. Os resultados evidenciam que os coordenadores possuem percepções positivas em relação ao evento associadas à importância para a formação integral dos alunos, para suprir uma lacuna e dar visibilidade à instituição. As práticas dos coordenadores, associadas ao planejamento e gestão do evento, por um lado seguem um rito desde a criação dos Jogos e, por outro, buscam inovações para atender as demandas de cada edição.

PALAVRAS-CHAVE: Jogos do instituto federal do paraná; Eventos esportivos; Esporte escolar; Coordenadores de ações esportivas
Matheus Amaral de Sousa

Graduação em Educação Física Universidade Estadual de Maringá, Departamento de Ciências do Movimento

Humano, Ivaiporã, Brasil matheusamaraldesousa@gmail.com ○https://orcid.org/0000-0003-2218-3605

Andréia Paula Basei

Doutora em Educação

Universidade Estadual de Maringá, Departamento de Ciências do Movimento Humano, Ivaiporã, Brasil andreiabasei@yahoo.com.br ○https://orcid.org/0000-0002-6675-6076 
The games of the Federal Institute of Paraná: a study on the perceptions and practices of sports action coordinators

\begin{abstract}
This study aimed to analyze the perceptions and practices of the IFPR sports action coordinators about the Games of the Federal Institute of Paraná. This is a descriptive qualitative research, in which a semi-structured interview was applied with the four coordinators involved with the management of the JIFPR from 2010 to 2021. Data were categorized and analyzed through content analysis. Through the speeches, it was possible to apprehend the constructions, relationships and importance of this event in the context in analysis. The results show that the coordinators have positive perceptions about the event associated with its importance for the integral education of students, to fill a gap and give visibility to the institution. The coordinators' practices, associated with the planning and management of the event, on the one hand follow a rite since the creation of the Games and, on the other, seek innovations to meet the demands of each edition.
\end{abstract}

KEYWORDS: Games of the federal institute of paraná; Sports event; School sports; Sports action coordinators

\title{
Los juegos del Instituto Federal de Paraná: un estudio sobre las percepciones y prácticas de los coordinadores de acción deportiva
}

\section{RESUMEN}

Este estudio tuvo como objetivo analizar las percepciones y prácticas de los coordinadores de acción deportiva de la IFPR sobre los Juegos del Instituto Federal de Paraná. Se trata de una investigación descriptiva cualitativa, en la que se aplicó una entrevista semiestructurada con los cuatro coordinadores involucrados con la gestión de la JIFPR de 2010 a 2021. Los datos fueron categorizados y analizados mediante análisis de contenido. A través de los discursos fue posible aprehender las construcciones, relaciones e importancia de este evento en el contexto analize. Los resultados muestran que los coordinadores tienen percepciones positivas del evento asociadas a su importancia para la educación integral de los estudiantes, para llenar un vacío y dar visibilidad a la institución. Las prácticas de los coordinadores, asociadas a la planificación y gestión del evento, por un lado siguen un rito desde la creación de los Juegos y, por otro, buscan innovaciones para satisfacer las demandas de cada edición.

PALABRAS-CLAVE: Juegos del instituto federal de paraná; Evento deportivo; Deportes escolares; Coordinadores de acción deportiva 


\section{INTRODUÇÃO}

Os Institutos Federais de Educação, Ciência e Tecnologia foram instituídos a partir da Lei n. 11.892, de 29 de dezembro de 2008, definidos como:

[...] instituições de educação superior, básica e profissional, pluricurriculares e multicampi, especializados na oferta de educação profissional e tecnológica nas diferentes modalidades de ensino, com base na conjugação de conhecimentos técnicos e tecnológicos com as suas práticas pedagógicas (BRASIL, 2008).

No ato de criação, foram implantadas 38 unidades distribuídas nos diversos estados brasileiros. No estado do Paraná, atualmente, o Instituto Federal conta com 25 campi localizados nas cidades de: Arapongas, Assis Chateaubriand, Astorga, Barracão, Campo Largo, Capanema, Cascavel, Colombo, Coronel Vivida, Curitiba, Foz do Iguaçu, Goioerê, Jacarezinho, Jaguariaíva, Irati, Ivaiporã, Londrina, Palmas, Paranaguá, Paranavaí, Pinhais, Pitanga, Quedas do Iguaçu, Telêmaco Borba, Umuarama e, União da Vitória.

Os Institutos Federais possuem como missão a promoção da educação profissional, científica e tecnológica, pública, gratuita e de excelência, por meio de atividades de ensino, pesquisa e extensão, visando à formação integral de cidadãos críticos, empreendedores, comprometidos com a sustentabilidade e com o desenvolvimento local, regional e nacional, abrangendo todos os níveis e modalidades de ensino (BRASIL, 2008).

Dada esta missão, um dos mecanismos criados para a sua efetivação foi a criação dos Jogos dos Institutos Federais de Educação (JIFs). Trata-se de um evento esportivo promovido pelo governo federal, através da Secretaria de Educação Profissional e Tecnológica do Ministério da Educação (MEC) que tem como finalidade promover a educação, a integração e a formação por meio do esporte. Esta finalidade coaduna com os apontamentos de Nascimento, Palhano e Oeiras (2007) de que em vários países são realizadas competições em nível escolar como atividade extracurricular, como forma de melhorar a qualidade da educação. Sawitzki (2008, p. 8) ao se referir a realização de jogos escolares também destaca que devem proporcionar "atividades de formação/socialização, formação esportiva, aquisição de competências físicas, técnicas e táticas, contribuindo com a formação integral do jovem cidadão e do desportista”.

O evento é dividido em três etapas, sendo elas: estadual, regional e nacional. Esta pesquisa tem como foco a primeira etapa dos Jogos que ocorre em âmbito estadual, mais especificamente, os Jogos do Instituto Federal do Paraná (JIFPR). Nesta etapa, os Jogos contam com a participação dos estudantes dos diversos campi do IFPR e são organizados pelos coordenadores de ações esportivas vinculados ao campus sede localizado na capital do Estado. 
De acordo com informações constantes na página do IFPR a coordenadoria de ações esportivas tem a missão de desenvolver atividades e ações através da participação permanente de técnicos e comunidade em geral visando a melhoria do lazer e da qualidade de vida das comunidades relacionadas ao IFPR. Destacando-se como objetivos otimizar espaços para o desenvolvimento científico do esporte, lazer e qualidade de vida; oferecer local apropriado para capacitação de recursos humanos (equipes, professores, técnicos e comunidade esportiva em geral relacionado ao desenvolvimento do esporte, lazer e qualidade de vida) e; trazer a iniciativa privada como parceira no gerenciamento destes espaços, arrecadando novos recursos para o desenvolvimento do esporte, lazer e qualidade de vida.

Nesse contexto, os coordenadores de ações esportivas são entendidos como os agentes esportivos fundamentais no direcionamento de todo o processo de gestão do JIFPR. Destaca-se que o entendimento de "agentes" vai ao encontro ao conceito proposto por Bourdieu (2011) como aqueles

[...] que atuam e que sabem, dotados de um senso prático [...], de um sistema adquirido de preferências, de princípios de visão e de divisão (o que comumente chamamos de gosto), de estruturas cognitivas duradouras (que são essencialmente produto da incorporação de estruturas objetivas) e de esquemas de ação que orientam a percepção da situação e a resposta adequada (BOURDIEU, 2011, p. 42).

Justifica-se a relevância deste estudo dada a carência de estudos que procuraram investigar os Jogos do Instituto Federal do Paraná nos diferentes âmbitos e perspectivas de análise. Destaca-se a inexistência de produção científica acerca do objetivo desta pesquisa em analisar as percepções dos coordenadores de ações esportivas do IFPR diretamente ligados a gestão dos Jogos do Instituto Federal do Paraná no período de 2010 a 2021.

\section{Metodologia}

Esta pesquisa trata-se de uma investigação de natureza qualitativa descritiva. Conforme Minayo (2013), esse tipo de pesquisa é aplicado aos estudos que buscam investigar as percepções, os pensamentos, as opiniões ou interpretações dos humanos nas relações como vivem e constroem seus produtos pessoais, possibilitando desvelar os processos sociais característicos de um grupo ou outro fenômeno em estudo, aumentando, gradativamente, a compreensão do fenômeno em investigação.

A pesquisa foi desenvolvida tendo como participantes os quatro coordenadores de ações esportivas do Instituto Federal do Paraná (IFPR), durante o período de 2010 a 2021. Os coordenadores de ações esportivas são responsáveis pela gestão dos Jogos do Instituto Federal do 
Paraná (JIFPR) e desenvolvem ou desenvolveram suas atividades no cargo no campus sede do IFPR em Curitiba, Paraná.

Os critérios para seleção dos participantes foram: a) ter exercido a função de coordenador de ações esportivas no IFPR no período da pesquisa; b) desenvolver atividades relacionadas ao gerenciamento dos JIFPR; c) aceitar participar da pesquisa mediante assinatura da Autorização para a Pesquisa e do Termo de Consentimento Livre e Esclarecido conforme normas estabelecidas pelo Comitê de Ética em Pesquisa. Perante os critérios aludidos, os quatro coordenadores que exerceram o cargo no período aceitaram participar da pesquisa e estão caracterizados no Quadro 1. Vale ressaltar que para assegurar os princípios éticos da pesquisa foram utilizados códigos (CAE1, CAE2, CAE3 e CAE4) para identificação dos participantes.

Quadro 1 - Caracterização dos participantes da pesquisa

\begin{tabular}{|l|l|}
\hline CAE1 & $\begin{array}{l}\text { É do sexo masculino e possui } 61 \text { anos de idade. É graduado em Desenho (PUCPR) e em } \\
\text { Educação Física (UFPR), mestre em Educação Ciência e Tecnologia (UTFPR) e doutor em } \\
\text { Engenharia da Produção (UNIMEP). Atua no IFPR desde 2008. Exerceu o cargo de coordenador } \\
\text { de ações esportivas no período de 2008 à 2014. }\end{array}$ \\
\hline CAE2 & $\begin{array}{l}\text { É do sexo feminino e possui } 58 \text { anos de idade. É graduada em Educação Física pela Faculdade } \\
\text { de Educação Física do Norte do Paraná (1983), especialista em Ginástica Rítmica pela UNOPAR } \\
\text { e mestre em Educação Física pela UEM/UEL (2011). Atua no IFPR desde 2013. Exerceu o cargo } \\
\text { de coordenadora de ações esportivas no período de 2015 à 2016. }\end{array}$ \\
\hline CAE3 & $\begin{array}{l}\text { É do sexo masculino e possui } 48 \text { anos de idade. É graduado em Tecnólogo em Processamento de } \\
\text { Dados pela Sociedade Paranaense de Ensino e Informática (1993) e mestre em Informática pela } \\
\text { PUCPR (1999). Atua no IFPR desde 2010. Exerceu o cargo de coordenador de ações esportivas } \\
\text { no período de 2016 à 2018. }\end{array}$ \\
\hline CAE4 $4 \begin{array}{l}\text { É do sexo masculino e possui } 38 \text { anos de idade. É graduado em Comércio Exterior pela } \\
\text { Universidade Positivo (2001), possui especialização lato sensu em Desenvolvimento Regional } \\
\text { (2011) pela UFPR e Mestrado em Educação Física pela UFPR (2017). Atua no IFPR desde 2009. } \\
\text { Exerce o cargo de coordenador de ações esportivas a partir de 2018 até o momento atual (2021). }\end{array}$ \\
\hline
\end{tabular}
Fonte: Elaborado pelos autores (2021).

O instrumento de coleta de dados foi uma entrevista semiestruturada. A entrevista foi agendada previamente mediante apresentação do objetivo do estudo, aceitação em participar da investigação e assinatura dos documentos. As entrevistas foram realizadas de forma remota, individualmente, utilizando-se a plataforma Google Meet, possibilitando a interação síncrona com os participantes, bem como a gravação da interlocução. Posteriormente, as entrevistas foram transcritas na íntegra.

Os dados obtidos foram categorizados e analisados em conformidade com o método de análise de conteúdo, que consiste em um conjunto de técnicas de análise de comunicações, por meio de procedimentos sistemáticos e objetivos que possibilitam descrever os conteúdos das mensagens que compõem os dados de investigação (BARDIN, 2011). Deste modo, efetuou-se este procedimento a partir das três fases do método: a pré-análise, que consistiu na leitura flutuante e 
preparação do material; a exploração do material, sendo realizado o processo de codificação das informações, por meio de classificação e agregação do conteúdo; e o tratamento dos resultados e interpretações acerca das inferências e análise dos resultados obtidos na pesquisa (BARDIN, 2011).

$\mathrm{Na}$ análise de conteúdo foi empregado o método de análise categorial, que corresponde ao conjunto de elementos com título genérico, por meio do agrupamento de informações com características comuns (BARDIN, 2011). Sendo assim, as categorias da pesquisa foram estabelecidas a priori a partir dos temas elencados no roteiro da entrevista semiestruturada, sendo estas: a) a gênese e as motivações dos JIFPR; b) planejamento e gestão dos JIFPR; c) financiamento e; d) avaliação do evento.

\section{Apresentação e discussão dos resultados}

$\mathrm{Na}$ apresentação e discussão dos dados da pesquisa foram reunidos os conjuntos de elementos que evidenciam similitudes e os casos específicos de diferenciação no interior das categorias de análise, sendo tais conteúdos analisados nas sessões a seguir.

Antes, porém, de adentrar na apresentação e discussão das categorias especificamente, acredita-se na relevância de discutir as características dos participantes da pesquisa apresentadas no Quadro 1. Nota-se a predominância de ocupação do cargo por profissionais do sexo masculino. Conforme Amaral e Bastos (2016), no Brasil é comum encontrar um maior número de profissionais do sexo masculino ocupando os cargos de liderança no campo da gestão esportiva. Embora trata-se de uma tendência, enfatiza-se que o sexo dos profissionais não pode ser fator determinante para ocupar determinado cargo, mas sim, a formação e qualificação deste para exercer com excelência as suas funções.

Outra característica importante observada se refere à formação dos profissionais. Observouse que todos possuem formação em nível de mestrado e/ou doutorado, porém, somente o CAE2 possui toda sua formação voltada para a área da Educação Física. Para Campos Izquierdo et al. (2007) a existência de outros profissionais que executam funções relacionadas a gestão do esporte pode indicar uma falta de lógica entre a formação e a função que se executa.

Destaca-se, todavia, que este campo da gestão das ações esportivas da Instituição configurase como, nas proposições de Bourdieu (1983, p. 119), “[...] espaços estruturados de posições (ou de postos) cujas propriedades dependem das posições nestes espaços, podendo ser analisadas independentemente das características de seus ocupantes”. Dada a forma de ocupação do cargo, isto é, indicação e/ou convite da reitoria também observa-se a existência, ainda que implícita, do capital 
político como "[...] uma espécie de capital de reputação, um capital simbólico ligado à maneira de ser conhecido" (BOURDIEU, 2011, p. 204). Neste caso, percebe-se que o acúmulo deste capital está relacionado com a trajetória profissional desde o ingresso no IFPR, e que, de acordo com Starepravo, Souza e Marchi Jr. (2013, p. 795) “[...] muitas vezes, a posse de algumas variedades de capital, especialmente o capital social, político, e esportivo, se sobrepõe ao capital cultural específico na configuração do subcampo".

Deste modo, os profissionais que ingressaram para a docência na Instituição, configurandose como sua atividade principal, são chamados a assumir outros cargos e funções considerando não só o capital cultural de sua área do conhecimento, mas, também, outras formas de capital que o colocam em uma posição diferenciada dentro do campo de atuação.

\section{A gênese e as motivações dos JIFPR}

Para aprofundar a compreensão sobre o surgimento dos JIFPR, foram abordados na entrevista com os agentes esportivos aspectos históricos sobre o surgimento, a consolidação e as motivações dos Jogos. Sendo assim, inicialmente os coordenadores foram questionados e instigados a comentar sobre quando surgiram os JIFs e o JIFPR.

Olha o JIFS foi por causa de nós, JIFPR e JIFs Sul. [...] A gente percebia através de pesquisa, que era viável e possível. [...]. Após o JIFPR fizemos um convite para os Institutos da região sul: Santa Catarina, Rio Grande do Sul, três unidades e deu certo. O pessoal gostou da ideia, aí começamos a trabalhar em conjunto. Mas a primeira reunião, a primeira proposta, surgiu aqui em Curitiba, na nossa reitoria, através de mim e do Professor Paulo e daí por diante a coisa tomou outro rumo [...] é tudo uma questão de movimento que a gente criou e a coisa foi, hoje participam todas as unidades (CAE1).

[...] eu tenho esses dados, então eu posso te passar. Alguma data, sinceramente, de cabeça é meio complicado eu lembrar, mas a primeira competição, se não estou enganada foi em Palmas [...] 2009, 2010, agora eu não tenho mais certeza [...] (CAE2).

Foi em 2010 [...] surgiu o JIFPR, acho que foi em Assis, eu não lembro a cidade [...] não acompanhei, começo minha história de esporte em 2013 [...] (CAE3).

[...] o JIFs nacional, ele já havia. Os jogos da rede federal de educação profissional básica e tecnológica já eram disputados por outras instituições anterior ao JIFPR. [...] se eu não me engano o JIFPR, a primeira edição, foi realizada em $2010 \mathrm{ou}$ em 2011, eu não consigo precisar a data [...] os jogos nacionais no caso ele já era uma prática da rede federal [...] (CAE4).

Como é possível notar nas falas, somente os coordenadores CAE1 e CAE3 souberam informar precisamente o ano de surgimento dos Jogos, os demais entrevistados, embora demonstrassem conhecer alguns aspectos históricos, apresentaram dados ambíguos. Esse fato é 
compreensível devido ao fato de ocuparem o cargo em um período específico, não estar ligado à área da educação física/esporte, ou mesmo o período em que começaram a atuar no IFPR.

Conforme Vivan (2019), o primeiro Seminário Estadual de Esporte e Lazer do IFPR teve a participação de representantes de nove campi do Instituto Federal do Paraná, cujo tema central foi a realização da primeira edição dos JIFPR. Através deste seminário, promovido pela Coordenação de Ações Esportivas no dia 01 de outubro de 2010 em Curitiba, que foram propostas as ideias para o planejamento do evento, apresentadas as expectativas da reitoria e dos professores que atuavam em seus respectivos campi. Cada campus enviou um representante com formação em Educação Física ou colaborador para discutir a articulação para realização do $1^{\circ}$ Jogos Inter-campi do Instituto Federal do Paraná. Conforme a proposta inicial, o Seminário seria organizado uma vez por ano visando a troca de experiências entre os campi, a avaliação e reajuste das ações e projetos que envolvam a Política Estadual de Esporte, Lazer e Qualidade de Vida.

Ao pesquisar mais informações sobre a continuidade do Seminário, observou-se que a proposta de realização anual não foi concretizada. Porém, o objetivo central que foi a criação do JIFPR alcançou êxito, tendo em vista a realização da primeira edição dos Jogos ainda no ano de 2010 e, posterior a isso, a consolidação do evento esportivo observada na realização das demais edições anualmente no recorte temporal desta pesquisa.

Ainda com relação aos aspectos históricos, os coordenadores foram questionados sobre os idealizadores do evento. Também são identificados diferentes entendimentos sobre a questão. Evidencia-se nas falas que já aparecem alguns indicativos sobre as motivações para a criação e realização do evento.

Fui eu e o professor Francisco Paulo Trautwein, ele é da Paraná Esporte. [...] a vontade dos alunos e dos professores em fazer uma competição interna essa competição interna passou para regional e depois para nacional (CAE1).

No primeiro momento foi uma ação, surgiu como uma maneira de divulgar o Instituto como um todo. [...] eu me lembro de algumas pessoas que estavam na reitoria quando eu entrei, $[\ldots]$ quem eu sei que trabalhou muito, $[\ldots]$ que eu peguei nesta fase foi a partir de Rodrigo Navarro [...] (CAE2).

[...] quem sabe bem, assim, essa parte histórica é o professor CAE1 [...] essa parte histórica ele sabe muito bem, [...] eu sei que teve um professor chamado Francisco, talvez tenha sido ele que tenha idealizado. Nessa parte [...], eu não acompanhei, eu sei alguns nomes, eu conheci algumas pessoas [...] (CAE3).

Tem informações, nesse sentido que eu não sei muito a fundo, mas eu posso indicar também quem saberá, [...] professor CAE1 [...] e um professor que não está mais no quadro do IFPR que foram os idealizadores, eles que chamaram a responsabilidade de um momento que a instituição ainda estava se estruturando [...] (CAE4). 
Diante das informações presentes nas falas dos agentes, recorremos ao estudo de Vivian (2019) ao apontar que, o primeiro Reitor do IFPR, no ano de 2009, iniciou a estruturação da nova Reitoria, criando a Diretoria de Ações Esportivas, com um grupo que era formado pelo Prof. Renato Luiz do Nascimento e o Prof. Francisco Paulo Trautwien, um coordenador, um assistente administrativo e um estagiário de educação física. A Diretoria ficou na pró-reitoria de relações institucionais cuja missão é desenvolver atividades e ações esportivas do IFPR.

É perceptível nas falas dos entrevistados CAE2, CAE3 e CAE4, que o CAE1 tem uma relação com a criação do evento. Ambos afirmam que o CAE1 que poderia dar informações aprofundadas sobre o questionamento feito. Desta forma, fica claro na fala do CAE1 quem foram os idealizadores, junto a ele e o entorno daquelas proposições apresentadas. Conforme destacado nas falas, a realização de tais ações apresenta características típicas do que Oliveira (2012) fala sobre eventos, os quais podem gerar sensações, se tornar motivo de notícia, tanto dentro ou como fora da organização e seu êxito é algo relacionado as sensações que o público sente antes, durante e depois da realização do mesmo. Entretanto, há que se destacar o fato de que, por não atuar especificamente no campo esportivo, o conhecimento sobre estes aspectos se relaciona mais com o um tipo de capital simbólico e político da posição ocupada naquele momento do que propriamente ao capital cultural e esportivo construído dentro do campo.

Embora os entrevistados apresentaram indicativos na questão anterior, foi realização um questionamento específico sobre o conhecimento/entendimento deles sobre as motivações para a criação do JIFPR.

Quem é profissional de educação física milita nessa área também e na área de esportes. A gente percebeu que os nossos alunos tinham interesse em participar de competições, principalmente, as unidades do interior, elas são muito mais fortes, nesse sentido da competição [...] (CAE1).

Então, difícil, o que eu acredito que era uma lacuna [...], essa ânsia por essa competição se tornou tão grande. [...] os jogos dos Institutos assemelham-se as principais competições do país. Isso significa, antes de mais nada, uma ânsia por esses estudantes. Eu acredito em duas vertentes: o esporte cumpre um papel fundamental; [...] no segundo momento, na resposta imediata o quanto os estudantes necessitam desta proposta [...] (CAE2).

Acredito que a própria falta. Eu não tenho essa informação, então eu estou supondo, a falta obviamente [...] de um evento nesse âmbito na Instituição, a própria de marcação de espaços que devem ser ocupados na Instituição. A nossa instituição carente de algo voltado para esse campo agora da educação, que é o campo do esporte educacional [...] então eu acredito que pela falta de estrutura, condicionada a uma libertação [...] (CAE4). 
Os elementos em destaque nas falas dos coordenadores se referem a suprir uma lacuna institucional considerando os interesses apresentados pelos alunos e docentes e também a visibilidade proporcionada pelo evento para a Instituição. Sarmento et al (2011, p. 79) corroboram para o entendimento destas falas ao afirmar que

[...] o evento é um excepcional catalisador para o desenvolvimento seja em que contexto for. No âmbito muito próprio do Desporto esta potencialidade tem vindo a ganhar uma dimensão cada vez maior, em função da forma como a atual sociedade pós-moderna valoriza o entretenimento, a diversão e o prazer.

De igual modo, Constantino (2006 apud SARMENTO et al, 2011, p. 94) refere que o evento desportivo pode ser um excelente fator de notoriedade para quem o organiza, para quem participa e para o local onde tem lugar.

Dadas estas motivações iniciais para a criação do evento, os coordenadores foram inquiridos sobre a importância da consolidação do evento, tendo em vista que está atrelado a várias pessoas, tanto os estudantes, servidores do IFPR, quanto com a comunidade externa.

Eu acho que o JIFs é um momento de alegria para alunos, para os servidores, técnicos administrativos [...]. É uma boa competição, porque é difícil acontecer alguma coisa irregular nesses jogos, de brigas, alguma coisa parecida, pelo contrário, existe uma competição também e eu vejo que a primeira competição que é sadia nesse sentido [...] (CAE1).

[...] ele foi o evento que selecionava os estudantes, as equipes campeãs, nas modalidades coletivas e os individuais para participarem do JIFs Sul representar o IFPR nos jogos regionais [...] posteriormente no Nacional [...] (CAE4).

Nas falas acima, são apresentadas duas perspectivas diferentes, a primeira relacionada ao envolvimento de inúmeras pessoas e o momento de celebração que envolve os Jogos e, a segunda, com um olhar técnico seletivo característico do esporte e das competições esportivas, mas que pelas características descritas na fala do CAE1 figuram na dimensão educacional do esporte, possibilitando aos envolvidos a interação, a construção de valores sociais e a aprendizagem do esporte em si. Sarmento et al (2011, p. 94) destaca que o evento esportivo é uma "interface entre quem o idealiza, o produz e o consome de forma direta ou indireta. [...] um espaço de interação entre territórios comunicacionais bem diferentes, nos quais as expectativas raramente são coincidentes, mas complementares".

Reverdito et al. (2008), corroboram com o entendimento observado na fala dos entrevistados, pois,

O esporte encontra na escola uma grande representatividade. A competição é um dos conteúdos do esporte, logo a escola não pode negar nem o esporte e nem a competição. Porque ambos emanam e compõem a essencialidade complexa de um fenômeno sociocultural. Um sem o outro perderiam em essência o que os caracteriza (REVERDITO, et al. 2008). 
Por conseguinte, ressalta-se que a competição está por toda parte da sociedade e isso acaba tendo olhares negativos. Ao encarar a continuidade do esporte de uma forma que valorize a competição, isso guiará os jovens, fazendo com que aprendam a lidar com seus próprios limites e a superar desafios. Entretanto, o esporte pode ser visto como um reflexo de valores sociais, aspecto que os professores de educação física devem estar atentos, para que as competições exageradas não se tornem o principal objetivo da educação física no âmbito educacional.

\section{Planejamento e gestão dos JIFPR}

Analisando as respostas dos questionamentos referentes ao planejamento e gestão do evento, é notável, de modo geral, que existe um grupo de pessoas, do qual fazem parte servidores administrativos e professores do próprio IFPR responsável por planejar e gerenciar o evento, tanto na parte técnica, quanto administrativa. O grupo expõe suas ideias para cada edição do evento, levando em consideração aspectos positivos e negativos das edições anteriores. Com isso, vislumbram a melhoria do evento, sempre tendo o recurso financeiro disponível como balizador das ações.

Em princípio, os coordenadores foram questionados sobre a escolha da cidade sede dos Jogos, em que foi possível identificar os critérios para determinar este aspecto do planejamento.

[...] normalmente, quando a gente inicia o ano ou finalizou o ano, sempre aparece os interessados, duas, três cidades se organizam para isso. Primeiro a gente avalia as condições, avaliamos a hotelaria, espaço físico para realização dos jogos [...] condições de deslocamento de um ginásio para o outro [...] (CAE1).

[...] esse planejamento, ele começa a cada vez que termina uma edição, você começa de uma maneira até informal, começa a analisar o que deu certo e o que não deu, quando você se reúne oficialmente para fazer uma avaliação da proposta anterior, [...] como é bom filtrar todas daquelas experiências e trazer para o processo avaliativo. No Instituto tem várias vantagens, por exemplo, o planejamento do principal, que o processo licitatório que ocorre no início do ano, senão você não tem tempo hábil de cumprir um roteiro que uma pró-reitoria tem e essa pró-reitoria ela tem vários outros processos para que o Instituto continue rodando no mesmo setor, então o nosso é apenas mais um [...] (CAE2).

[...] você lança essa pergunta de quem quer organizar [...] pergunta quais são os pré-requisitos, tem que ter um espaço para alimentação, tem que ter um espaço para hospedagem dos professores, dos alunos, da arbitragem assim [...] esses são os pré-requisitos tem que ter um ginásio de esportes [...] de preferência perto [...] organizar os jogos de maneira adequada (CAE3).

[...] geralmente os locais de competição eram até então definidos nas reuniões do colégio de dirigentes. Essas reuniões possuem um calendário oficial. Na reunião do colégio de dirigentes participam somente os dirigentes no caso diretores-gerais, 
pró-reitores, reitor e a partir dali é levado ao conselho superior onde decidem se homologam ou não aquele calendário [...] mas acho que lá no colégio de dirigentes acho que fazia a pergunta "quem quer sediar?" Eu imagino que era assim e depois da experiência de 2018 eu propus fazer quase como é feito, por exemplo, olimpíadas, aqueles projetos que coloca de obrigação ela tem que ter pelo menos isso é assim que tem que fazer [...] (CAE4).

Fica explícito nas falas que a determinação do campus que sedia cada edição dos Jogos é estritamente vinculada às condições físicas da Instituição e também, as condições da cidade sede, principalmente no quesito hospedagem e espaços para as competições. Esse fator, certamente justifica o fato de que a cidade de Palmas, por exemplo, sediou quatro vezes os JIFPR (2010, 2011, 2013 e 2019). As demais edições foram realizadas nas cidades de Assis Chateubriand (2012), Foz do Iguaçu (2014), Cascavel (2015), São José dos Pinhais (2016) e Umuarama (2018).

Considera-se também o fato de que, para a realização dos JIFPR não existe uma disponibilidade orçamentária específica para construção e/ou ampliação de instalações esportivas, fato que contribui para a escolha de cidades sede que já disponibilizam a estrutura mínima necessária. Outro fator é o ano e a forma de implantação do IFPR nos municípios, tendo em vista que aqueles cuja implantação ocorreu nos primeiros anos de surgimento da Rede Federal de Educação Profissional e Tecnológica em 2008, dispuseram de maior período de tempo para captação de recursos e melhorias nas estruturas do campus. Por outro lado, quanto a forma de implantação, o campus de Palmas, por exemplo, nasceu da desapropriação dos bens imóveis e laboratoriais do Centro Universitário Católico do Sudoeste do Paraná - UNICS (IFPR, 2021), em que, dentre outros cursos de graduação, era ofertado o curso de Educação Física, dispondo dessa maneira, de estrutura esportiva previamente.

Importante ressaltar que a insuficiência de estrutura física em muitos campi não influencia somente na realização de eventos, mas também, nas próprias práticas pedagógicas ligadas a educação física, tal qual, é exposto por Maranho (2019) ao relatar as práticas da disciplina de Educação Física no IFPR Campus Telêmaco Borba:

Apesar do elevado número de alunos, especialmente daqueles que cursam o Ensino Médio Integrado, e demandas de cunho esportivo existentes no âmbito da instituição, tais como Jogos do Instituto Federal do Paraná (JIFPR) e Programa Estudante Atleta (PEA) até o final do ano de 2018, assim como em muitos outros campi da instituição, Telêmaco Borba não possuía um espaço específico destinado à prática esportiva, uma quadra esportiva. Assim não havia quadras próximas ao Campus que pudessem ser utilizadas durante o horário das aulas, apenas em contraturno, para o desenvolvimento e treinamento de práticas esportivas específicas (MARANHO, 2019, p. 12).

Ainda sobre o aspecto estrutura física, as reflexões são ampliadas no sentido de entrelaçar os objetivos explícitos dos Jogos, isto é, educação, democratização, formação integral e humana com o 
processo de planejamento e gestão. Observa-se que com as finalidades expostas, e para ampliar as possibilidades de outros campi sediarem o evento, poderia recorrer-se a adaptação de espaços e materiais. Conforme Sawitzki (2008, p. 7) "Justifica-se a importância em adaptar os materiais, espaços físicos e algumas regras, tendo em vista que existem diferenças estruturais, cognitivas, motoras e afetivas entre um adulto e uma criança/adolescente na participação em atividades esportivas e jogos esportivos competitivos", tendo em vista que, "contrariando essas diferenças, geralmente os eventos esportivos competitivos organizados para os escolares apresentam-se na mesma lógica e estrutura dos eventos esportivos de adultos".

\section{Financiamento}

Outro aspecto importante no que tange ao planejamento e a gestão são os recursos financeiros disponibilizados para o evento. Os coordenadores foram questionados sobre quem disponibiliza esses recursos, quem gerencia, de que maneira é repassado e, se existe um valor fixo ou existe outro critério, como por exemplo, o número de participantes para receber proporcionalmente esse valor financeiro.

[...] é coordenado pela coordenação de educação física e coordenado pela DAES, a DAES faz um link os professores e aí nessas reuniões a gente faz são definidas estratégias se vamos participar ou se não vamos [...] um jogo de organização tudo vai depender do dinheiro, infelizmente [...] (CAE1).

[...] recurso público não pode ser diferente [...] às questões legais principalmente por se tratar de recursos públicos tinham que estar muito amarradas [...] nunca precisei responder nenhuma das ações [...] nunca teve nenhum problema com recurso público, sempre foi muito bem. [...] primeiro momento havia recursos em uma época de investimento, momento político diferenciado em que você poderia tratar essas questões do esporte [...] a partir do ano de 2016 esse recurso foi reduzido e os alunos no crescimento muito maior [...] (CAE2).

[...] passam por várias pessoas [...] para fazer né o planejamento, tem que dizer que está tudo bem [...] financeiro tem que dizer que tem dinheiro [...] auditoria tem que dizer que está tudo certo [...] todo um processo [...] (CAE3)

[...] o montante (recurso) para os eventos eu não tive acesso, a não ser nos anos em que eu estive à frente, o montante ele que havia sido separado para o trabalho [...] não é um evento barato [...]. A SETEC repassa o orçamento para o instituto e o instituto federal através da sua pró-reitoria de planejamento, convoca todos os diretores de cada unidade, seus pró-reitores, diretores gerais para uma reunião sobre a divisão dos recursos orçamentários [...] (CAE4).

Nota-se nas falas que, por se tratar de um financiamento por meio de recurso público o papel dos coordenadores é limitado ao planejamento, apresentando as demandas do evento para posteriores ajustes no orçamento de acordo a disponibilidade de recursos e a necessidade de seguir 
todos os trâmites burocráticos. Para Delicado (2003) o orçamento é uma estimativa das receitas e despesas durante o período de um ano, que deve ser elaborada e aprovado para que seja executado. Para isso é necessário realizar um processo de elaboração que é onde objetiva o plano de ação, assim como o plano estratégico e o plano de atividades.

Entretanto, com a consolidação do evento e o aumento no número de participantes não houve um aumento proporcional dos recursos disponibilizados. Esse fato fez com que surgisse a necessidade de criar critérios para selecionar seus participantes. Conforme os coordenadores, existe uma seleção dos alunos que se destacam em suas modalidades esportivas com o intuito de se tornarem mais competitivos, no sentido de ter um grupo com um nível maior de habilidade e assim conseguir melhores resultados.

[...] eu posso dizer do basquetebol que eu me envolvo, mas o que a gente faz [...] nessa competição para participar do grupo de uma seleção, aí a gente cria eventos e esses eventos [...] são oficinas de esportes, clínicas que a gente sempre leva alguém para esportes [...], treinamentos [...] (CAE1).

[...] na realidade, no início não havia nenhuma seleção, era (um pedido de) por favor venha participar, vamos lá divulgar o instituto[...] tinha dinheiro, mas [...] a gente chegou ao ponto de ter um número absurdo de estudantes e não ter recurso[...] é feito uma reunião [...] com diretor e abre o jogo para gente abrir uma prescrição [...] (CAE2).

[...] a gente criou clínicas esportivas, a gente pede que os coordenadores das modalidades selecionam um número $\mathrm{x}$ de atletas, da deslocamento, hospedagem e alimentação, dois a três dias lá. Esses coordenadores fazem a seleção das suas instituições, desse modo, a gente se tornou mais competitivo, a instituição se tornou mais competitiva porque a gente. A própria clínica já sofreu agente reduziu o número de estudantes que poderiam ser chamados para primeira seleção [...] são selecionados os estudantes que vão participar das próximas fases [...] (CAE4).

Ao analisar as repostas dos entrevistados quanto ao método de selecionar os alunos para participarem do evento, compreende-se que quando o evento tinha um percentual de recursos equivalente ao número de participantes, não era necessário existir métodos de selecionar os participantes. Quando no evento em nível estadual se tem um maior número de participantes e a quantidade de recurso para realização do evento não aumentou na mesma proporção, devido, inclusive, a cortes de verbas do governo federal destinados a educação, se torna necessário selecionar os participantes. Já em nível regional e nacional do evento, o intuito de selecionar é ter um grupo que tenha maiores chances de obter um lugar no pódio da competição. Todavia, a situação criada induz ao questionamento sobre as finalidades do evento, isto é, um evento cujo objetivo central é contribuir com uma educação de qualidade e com a integração, utilizar-se de critérios de seleção dos participantes pode ir de encontro aos seus propósitos iniciais. 
Considerando que a participação no evento tornou-se restrita a determinada porcentagem dos alunos da instituição, justificada em grande medida pelos entrevistados devido aos recursos, compreende-se que o caráter educacional do esporte proposto inicialmente pode estar sendo secundarizado pelo esporte competitivo, com características de seletividade, sobrepujança e competitividade. Contrariamente a este direcionamento, acredita-se que,

[...] a educação, que tem um fim eminentemente social, ao compreender o esporte como manifestação educacional, tem que exigir do chamado esporte-educação um conteúdo fundamentalmente educativo. [...] Portanto, as competições escolares devem ter um sentido educativo e não simplesmente reproduzir as competições de alto nível, [...] onde a prática esportiva como educação social será essencial no desenvolvimento de personalidades e indispensável no processo de emancipação dos jovens, quando prosseguimos com o argumento de que o esporte é um dos meios mais eficientes na formação dos mesmos (TUBINO, 2011, p.32).

Por outro lado, os relatos dos coordenadores e as características assumidas pelo evento evidenciam que "a instituição esportiva sempre lançou mão do argumento de que esporte é cultura, é educação, para legitimar-se no contexto social, e principalmente para conseguir apoio e financiamento oficial" (CAPARROZ, 2007, p. 22).

É comum os eventos esportivos, utilizarem parcerias, patrocinadores para custear as despesas da realização do evento. De acordo com Cardenas e Feuerschütte (2014) os gestores esportivos buscam maneiras de obter recursos financeiros, podendo ser nos meios públicos e também no privado para que consigam realizar seus eventos. Esses recursos podem ser conhecidos, no esporte, como patrocínios. Como maneira de dar um retorno para o patrocinador do evento, o gestor propõe que em seu evento será divulgado o patrocinador, seus produtos entre outros aspectos relacionados ao patrocinador.

Neste âmbito e considerando que o JIFPR é um evento ligado a uma Instituição de ensino pública, custeadas por recursos federais, questionamos se o evento teria algum tipo de parceria com empresas privadas, prefeituras ou até mesmo outros órgãos para que fosse possível a realização dos Jogos.

[...] não nada, nada, porque nós somos proibidos. [...] pelo cara ser bem meu amigo, consegui liberação de algumas praças para treinamento [...] vai muito do profissional, parceiras que eu digo de amigos, de empresas não, infelizmente [...] (CAE1).

[...] não, parceria a gente teria possibilidade de fazer algumas parcerias, desde que pessoas estivesse interessada em fazer, [...] daria para fazer, daria para fazer parcerias principalmente com as prefeituras [...] parceria com empresa seria o ideal, mas a gente não conseguiu fazer [...] (CAE3).

Conforme fica claro na fala dos gestores, esse evento não conta com parcerias para disponibilização de recursos financeiros, entretanto, no que se refere a locais para competições as 
prefeituras dos municípios sede auxiliam no atendimento as demandas geradas pelo evento.

\section{Avaliação do evento}

Por fim, os coordenadores foram inquiridos sobre a utilização de mecanismos de avaliação para o evento. Especificamente, os questionamentos tiveram como foco se no respectivo período de atuação no cargo de coordenação de cada um dos entrevistados, utilizava algum mecanismo para avaliar o evento em seus diferentes aspectos e considerando todos os envolvidos.

[...] sempre a gente faz uma avaliação técnica de alojamento alimentação [...] importante você conversar com CAE4 ou a professora P1, eles têm tudo isso [...], eu estou dizendo o que eu sei sabe, mas eles sabem mais aprofundado até como se trabalha essa avaliação. Isso é uma coisa muito clara, então a gente respeita o aluno a gente quer que ele seja respeitado [...] (CAE1).

[...] ela acontece de uma maneira informal, nós professores, temos vários... com o grupo específico dos jogos a gente já começa a trocar as primeiras informações, num segundo momento, depois que baixou um pouquinho a poeira é feito um questionário avaliativo e encaminhado aos participantes [...] (CAE2).

[...] na verdade não tem avaliação. Normalmente, só tem as avaliações negativas, quando dá problema, daí as pessoas entram em contato, mas avaliação que seria o ideal de fazer a pesquisa com todos os alunos, com todos os professores, isso a gente acaba não fazendo (CAE3).

[...] a gente aplicou um questionário de avaliação, tanto no JIFPR de Umuarama quanto no término do JIFPR de Palmas. Esses questionários entram como documentos que subsidiam todo o planejamento para o ano seguinte, os próprios processos que a gente faz para realizar clínicas, JIFs Sul, JIFs Nacional. Os processos licitatórios em si, todos eles, assim a gente vai fazendo e vai trazendo de um ano para o outro [...] (CAE4).

As respostas evidenciam contradições sobre a existência de uma avaliação formal do evento. O CAE1 e CAE4 relatam que existia e utilizavam uma avaliação formal, já o CAE2 relata que existia uma avaliação, porém, ocorria de maneira informal. O CAE3 relata que seria o ideal existir uma avaliação, porém ela não era realizada. Embora as informações evidenciem a deficiência deste aspecto, nota-se que os coordenadores atribuem certa importância a avaliação como balizadora de ações futuras frente a gestão do evento, seja em termos de hospedagem e alimentação, de estruturas físicas e recursos humanos, ou até mesmo questões mais técnicas que envolvem as modalidades em disputa, tais como arbitragem. Depreende-se a partir destas análises que este é um ponto que merece mais atenção por parte dos coordenadores de ações esportivas que atuam frente aos JIFPR, tendo em vista que a avaliação se constitui em um elemento fundamental do processo de planejamento e gestão. 
Coutinho (2010) corrobora com este entendimento ao afirmar que a avaliação técnica, administrativa e avaliação dos participantes fazem parte do processo de encerramento, é através dessas avaliações que o gestor e a organização do evento terá as informações sobre os resultados que foram obtidos, podendo também ter informações dos pontos positivos e negativos durante toda a realização do evento. Realizar uma análise das avaliações é fundamental para que em edições futuras, possam estar aprimorando o evento.

Por outro lado, a partir de um olhar mais pedagógico sobre os jogos no contexto escolar, Sawitzki (2008) ressalta a importância de

desenvolver um processo de avaliação com a participação dos envolvidos, visando a verificação do cumprimento/superação das metas e objetivos propostos e, assim, provocar a reflexão sobre as ações didático-pedagógicas formativas ocorridas ou não durante o processo. [...] a presença de qualquer atividade no espaço da escola deve ser analisada e refletida pelo coletivo da comunidade escolar em que estiver inserida, para que possa the dar sentido e significado enquanto uma atividade formativa presente no projeto educacional (SAWITZKI, 2008, p. 9).

O autor sugere alguns parâmetros para avaliação dos jogos, tais como: organização do evento, atendimento/superação dos objetivos formativos e metas propostas, ações e reações pedagógicas, participação, responsabilidade, cooperação, colaboração, socialização e tolerância de cada segmento da comunidade escolar, convívio com momentos de adversidade, ação individual e coletiva na execução de tarefas e na tomada de decisão na busca de reorientar as ações didáticopedagógicas (SAWITZKI, 2008, p. 9).

\section{Conclusão}

Em face das análises relativas as percepções dos coordenadores de ações esportivas do IFPR diretamente ligados a gestão dos Jogos do Instituto Federal do Paraná no período de 2010 a 2021 , entende-se ter sido relevante dar voz a estes agentes, pois, a partir dos seus discursos, apreende-se as construções, relações, problemas e importância deste evento no contexto institucional e social.

De maneira geral, observou-se que os coordenadores possuem uma percepção muito positiva sobre a criação e consolidação dos Jogos dada a sua relação com os objetivos institucionais voltados a formação integral de cidadãos críticos promovendo a educação, a integração e a formação por meio do esporte. Essa percepção também parece estar alicerçada na necessidade de suprir uma lacuna percebida por toda a instituição, tanto em questões de qualidade educacional quanto na visibilidade perante a sociedade e mesmo no cenário regional e nacional, considerando que o evento acontece em diferentes etapas. 
No que se refere a todos os aspectos envolvidos no planejamento e gestão do evento, observa-se que algumas práticas se tornaram habituais, a citar os critérios para escolha do campus sede dos Jogos. Outras, entretanto, foram sendo modificadas de acordo com as demandas, como a necessidade de selecionar os alunos participantes. Observou-se que os coordenadores possuem funções que devem ser desempenhadas de forma compartilhada com outros setores da instituição, a exemplo, o setor financeiro devido todos os tramites burocráticos para utilização e prestação de contas de recursos públicos. Ressalta-se ainda, a necessidade percebida pelos coordenadores de aprimorar alguns aspectos da gestão, tais como o processo de avaliação do evento que ocorre somente de maneira informal.

Por fim, ressalta-se a importância de pesquisar e compreender o contexto de realização de eventos esportivos no âmbito educacional para compreender os dilemas, desafios e proposições implícitos e explícitos no planejamento e gestão dos JIFPR. Ao ampliar as discussões sobre o tema partindo do olhar dos principais envolvidos na gestão, bem como as perspectivas balizadoras destes olhares é possível refletir sobre o lugar que o evento vem ocupando no âmbito institucional e social.

Fica como sugestão de pesquisas futuras uma análise mais aprofundada sobre os documentos que estabelecem as diretrizes para o evento, orçamentos, regulamentos dos Jogos entre outros que possibilitem reflexões no âmbito teórico para, posterior, possível cruzamento de informações com perspectivas empíricas, semelhantes a estas apresentadas pelos coordenadores. Outro ponto pertinente para investigações futuras são as percepções dos estudantes do IFPR sobre as motivações e possibilidades de engajamento para participar dos Jogos. Além disso, indica-se para estudos futuros, uma exploração mais aprofundada sobre a importância social do evento para as cidades sede.

\section{REFERÊNCIAS}

AMARAL, Cacilda Mendes dos Santos; BASTOS, Flávia da Cunha. O perfil do gestor de instalações esportivas do município de São Paulo. Revista de Gestão e Negócios do Esporte, v. 1, n. 1, p. 50-63, maio 2016. Disponível em: 〈http://revistagestaodoesporte.com.br/mod/page/view.php?id=76>. Acesso em: $15 \mathrm{abr}$. 2021.

BARDIN, Laurence. Análise de Conteúdo. Lisboa, Portugal: Edições 70, 2011.

BRASIL. Lei $\mathbf{n}^{\mathbf{0}}$ 11.892, de 29 de dezembro de 2008. Institui a Rede Federal de Educação Profissional, Científica e Tecnológica, cria os Institutos Federais de Educação, Ciência e Tecnologia, e dá outras providências. 2008. Diário Oficial da União, Brasília, DF, 30 dez. 2008. Disponível em: <http://www.planalto.gov.br/ccivil_03/_ato2007-2010/2008/lei/111892.htm>. Acesso em: 20 mar. 2021.

BOURDIEU, Pierre. Questões de sociologia. Rio de Janeiro: Marco Zero, 1983. 
BOURDIEU, Pierre. Razões práticas: sobre a teoria da ação. 11. ed. Campinas, SP: Papirus, 2011.

CÁRDENAS, Alfredo Ribeiro; FEUERSCHÜTTE, Simone Ghisi. Atuação de gestores esportivos: atividades e responsabilidades. Revista intercontinental de gestão desportiva-RIGD, v. 4, n. 2, p. 271-283, 2014. Disponível em:

$<$ http://www.revista.universo.edu.br/index.php?journal=gestaoesportiva\&page=article \&op=viewArticle\&pat h\%5B\%5D=1415>. Acesso em: 22 maio 2021.

CAMPOS IZQUIERDO, Antonio et al. Los profesionales de la organización y gestión de actividad física y deporte en las instalaciones deportivas y entidades: características socio-demográficas y formativas. Revista Internacional de Ciências del Deporte, v. 3, n. 8, p. 25-38, 2007. Disponível em: 〈https://www.cafyd.com/REVISTA/ojs/index.php/ricyde/article/ view/42>. Acesso em: 26 ago. 2021.

CAPARROZ, Francisco Eduardo. Entre a educação física na escola e a educação física da escola: a educação física como componente curricular. 3. Ed. Campinas, SP: Autores Associados, 2007.

COUTINHO, Helen Rita Menezes. Organização de eventos. Ed. E-TEC Brasil, Manaus-AM, 2010.

DELICADO, Nuno. Manual de gestão desportiva. SportImpact, 2003. 154 p.

MARANHO, Mariana Ciminelli. Cadê a quadra, professora? Um relato de experiência da educação física no ensino médio do instituto federal do paraná, campus Telêmaco Borba. Revista Ciência é Minha Praia, p. 10-16, 2019. Disponível em:

<http://infoprojetos.com.br:8035/revistas/index.php/Cienciaminhapraia/article/view/198>. Acesso em: 7 mar. 2021.

MINAYO, Maria Cecília Souza. O desafio do conhecimento: pesquisa qualitativa em saúde. $13^{\mathrm{a}}$ ed. São Paulo, SP: Hucitec, 2013.

NASCIMENTO, Márcio Goes do; PALHANO, Danilo; OEIRAS, Janne Yukiko Yoshikawa. Competições escolares: uma alternativa na busca pela qualidade em educação. In: Simpósio Brasileiro de Informática na Educação, 18, 2007, São Paulo. Anais... São Paulo: [s. n.], 2007. p. 284-287.

OLIVEIRA, Maria Regina Carvalho Teixeira; BARCELOS, Luciano Henrique. Eventos esportivos: uma ferramenta mercadológica da escola particular. Lumina - Revista da Faculdade de Comunicação/UFJF, [S. 1.], v. 6, n. 1, 2012. DOI: 10.34019/1981-4070.2012.v6.21030. Disponível em:

<https://periodicos.ufjf.br/index.php/lumina/article/view/21030〉. Acesso em: 10 jun. 2021.

REVERDITO, Riller Silva et al. Competições escolares: reflexão e ação em pedagogia do esporte para fazer a diferença na escola. Revista Pensar a Prática, [S. 1.], v. 11, n. 1, p. 37-45, 2008. DOI:

10.5216/rpp.v11i1.1207. Disponível em: 〈https://www.revistas.ufg.br/fef/article/view/1207〉. Acesso em: 23 jul. 2021.

SARMENTO, José Pedro et al. O evento desportivo: etapas, fases e operações. Revista Intercontinental de Gestão Desportiva, v. 1, n.2, p. 78-96, 2011. Disponível em:

$<$ http://www.revista.universo.edu.br/index.php?journal=gestaoesportiva\&page=article\&op=viewArticle\&pat h\%5B\%5D=411>. Acesso em: 23 maio 2021.

SAWITZKI, Rosalvo Luis. Esporte Escolar: aspectos pedagógicos e de formação humana. Revista

Motrivivência, n. 31, p. 132-142, dez. 2008. DOI: https://doi.org/10.5007/2175-8042.2008n31p132.

Disponível em: <https://periodicos.ufsc.br/index.php/motrivivencia/article/view/2175-8042.2008n31p132>.

Acesso em: 23 jul. 2021.

STAREPRAVO, Fernando Augusto; SOUZA, Juliano de; MARCHI JR., Wanderley. Políticas públicas de esporte e lazer no Brasil: uma argumentação inicial sobre a importância da utilização da teoria dos campos 
de Pierre Bourdieu. Revista Brasileira de Ciências do Esporte, v. 35, n. 3, pp. 785-798, 2013. Disponível em: <https://doi.org/10.1590/S0101-32892013000300018〉. Acesso em 10 out. 2021.

TUBINO, Manuel José Gomes. Dimensões sociais do esporte. 3. ed. São Paulo: Cortez, 2011.

VIVAN, Aline Tschoke. Entrevista com Renato Luiz do Nascimento, Aparecida Bernardete Gaion, Emílio Rudolfo Fey Neto, André Santos Cancella. Revista Ciência é Minha Praia, p. 62-68, 2019. Disponível em: 〈http://infopguaifpr.com.br/revistas/index.php/Cienciaminhapraia/article/view/203/212>. Acesso em: 7 mar. 2021

\section{NOTAS DOS AUTORES}

AGRADECIMENTOS - Não se aplica.

FINANCIAMENTO - Não se aplica.

CONSENTIMENTO DE USO DE IMAGEM - Não se aplica.

APROVAÇÃO DE COMITÊ DE ÉTICA EM PESQUISA

Possui aprovação do comitê de ética. CAE 52657421.2.0000.0104

CONFLITO DE INTERESSES - Não possui conflito de interesses.

\section{LICENÇA DE USO}

Os autores cedem à Motrivivência - ISSN 2175-8042 os direitos exclusivos de primeira publicação, com o trabalho simultaneamente licenciado sob a Licença Creative Commons Attribution Non-Comercial ShareAlike (CC BY-NC SA) 4.0 International. Esta licença permite que terceiros remixem, adaptem e criem a partir do trabalho publicado, desde que para fins não comerciais, atribuindo o devido crédito de autoria e publicação inicial neste periódico desde que adotem a mesma licença, compartilhar igual. Os autores têm autorização para assumir contratos adicionais separadamente, para distribuição não exclusiva da versão do trabalho publicada neste periódico (ex.: publicar em repositório institucional, em site pessoal, publicar uma tradução, ou como capítulo de livro), com reconhecimento de autoria e publicação inicial neste periódico, desde que para fins não comerciais e compartilhar com a mesma licença.

\section{PUBLISHER}

Universidade Federal de Santa Catarina. Programa de Pós-Graduação em Educação Física. LaboMídia - Laboratório e Observatório da Mídia Esportiva. Publicado no Portal de Periódicos UFSC. As ideias expressadas neste artigo são de responsabilidade de seus autores, não representando, necessariamente, a opinião dos editores ou da universidade.

\section{EDITORES}

Mauricio Roberto da Silva, Giovani De Lorenzi Pires, Rogério Santos Pereira.

\section{EDITOR DE SEÇÃO}

Bianca Poffo

\section{REVISÃO DO MANUSCRITO E METADADOS}

João Caetano Prates Rocha; Keli Barreto Santos; Juliana Rosário

\section{HISTÓRICO}

Recebido em: 08 setembro 2021

Aprovado em: 02 novembro 2021 